\title{
HOPX homeobox methylation in differentiated thyroid cancer and its clinical relevance
}

\author{
Erika Urbano Lima 1,2, * Ileana G S Rubio ${ }^{1,2, *}$, Joaquim Custodio Da Silva ${ }^{3,4}$, Ana Luiza Galrão, \\ Danielle Pêssoa ${ }^{3,4}$, Taise Cerqueira Oliveira ${ }^{3}$, Fabiane Carrijo ${ }^{3,4}$, Igor Silva Campos ${ }^{5}$, \\ Luciano Fonseca Espinheira, ${ }^{5,6}$, Luiz Jose Sampaio7, Claudio Rogerio Lima ${ }^{8}$, Janete Maria Cerutti ${ }^{2,9}$ and \\ Helton Estrela Ramos ${ }^{3,4}$ \\ ${ }^{1}$ Biological Science Department, Thyroid Molecular Sciences Laboratory, Universidade Federal de São Paulo, São Paulo, Brazil \\ ${ }^{2}$ Structural and Functional Biology Program, Universidade Federal de São Paulo, São Paulo, Brazil \\ ${ }^{3}$ Department of Bio-regulation, Thyroid Study Laboratory, Health \& Science Institute, Federal University of Bahia, Salvador, Brazil \\ ${ }^{4}$ Post-graduate Program in Interactive Processes of Organs and Systems, Health \& Science Institute, Federal University of Bahia, Salvador, Brazil \\ ${ }^{5}$ Department of Pathology, Sao Rafael Hospital, Salvador, Brazil \\ ${ }^{6}$ Department of Anatomic Pathology \& Legal Medicine, Bahia Federal Medical School, Federal University of Bahia, Salvador, Brazil \\ ${ }^{7}$ Nuclear Medicine Department, Sao Rafael Hospital, Salvador, Brazil \\ ${ }^{8} \mathrm{Head}$ and Neck Surgery Department, Sao Rafael Hospital, Salvador, Brazil \\ ${ }^{9}$ Division of Genetics, Department of Morphology and Genetics, Genetic Basis of Thyroid Tumors Laboratory, Paulista School of Medicine, Universidade \\ Federal de São Paulo, São Paulo, Brazil
}

Correspondence should be addressed to H E Ramos: ramoshelton@gmail.com

*(E U Lima and I G S Rubio contributed equally to this work)

\begin{abstract}
Background: The inactivation of the tumor-suppressor homeodomain-only protein $\mathrm{X}$ (HOPX) usually involves promoter methylation in several cancer types. This study aimed to investigate the HOPX- $\beta$ mRNA expression and promoter methylation and their clinical relevance in differentiated thyroid cancer (DTC).

Patients and methods: Clinicopathological data and paraffin-embedded thyroid tumor tissues from 21 patients with DTC and 6 with benign tumors (T) and their non-tumor parenchyma (NT) were investigated. Tumor cell lines (FTC238, FTC236 and WRO) were treated with demethylating agent. $H O P X-\beta$ mRNA expression was assessed by qRT-PCR and methylation status by Q-MSP. Thyroid cancer data from Cancer Genome Atlas (TCGA) was also collected.

Results: HOPX- $\beta$ mRNA re-expression in two cell lines treated with demethylating agent was observed concomitantly with reduced promoter methylation. Reduced mRNA expression in T group compared to their NT was observed, and reduced protein expression in T compared to NT was observed in three cases. Low mRNA expression with high methylation status was detected in 6/14 DTC samples. High methylation status was associated with older age at diagnosis, recurrent or progressive disease and with the presence of new neoplasm event post initial therapy while hyper-methylation correlated with worse overall survival, worse disease-free status and older age.

Conclusion: A moderate coupling of downregulation of $H O P X-\beta$ mRNA expression in DTC followed by high HOPX- $\beta$ promoter methylation was observed however; high HOPX promoter methylation status was associated with the worse prognosis of DTC patients.
\end{abstract}

Endocrine Connections (2018) 7, 1333-1342
() 2018 The authors Published by Bioscientifica Ltd
Key Words

- HOPX

- methylation

- differentiated thyroid cancer

- epigenetic https://ec.bioscientifica.com https://doi.org/10.1530/EC-18-0380

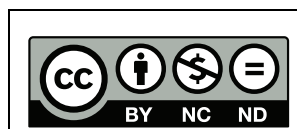

This work is licensed under a Creative Commons Attribution-NonCommercial-NoDerivatives 4.0 International License. 


\section{Introduction}

Differentiated thyroid cancer (DTC) has continued to increase over the past several decades, likely due to enhanced detection $(1,2)$. Cancer research, in general, has benefited greatly from many of the new scientific technologies such as DNA microarray, proteomic techniques and epigenetic profile analysis (3) which have ushered in the discovery of novel biomarkers and targets for drug design. More specifically, thyroid carcinogenesis and progression has been shown to be affected by a growing number of DNA alterations in tumor-suppressor genes, especially via gene promoter methylation (4) causing a silencing of tumor-suppressor genes that are linked to apoptosis or DNA repair $(5,6)$. A better understanding of such modifications may open the way to host innovative targeted therapies in DTC.

The homeodomain-only protein X (HOPX) (Ensembl: ENSG00000171476) inhibits gene transcription through sequestration of serum-responsive factor and recruitment of histone deacetylase (7). HOPX has been implicated in contributing to the epigenetic regulation of differentiationassociated genes, encompassing crucial oncoproteins such as angiogenic growth factor of CYR61, cell-surface proteins such as EMP1 and EPHA2, transcriptional factor such as c-Fos, EGR1 and metabolism-related genes like GLUT3 $(8,9,10)$. It is omnipresent in a large cluster of normal tissue, but less in malignant samples including choriocarcinoma, endometrial, lung and gastrointestinal (GI) cancers $(8,10,11,12,13)$. It has been demonstrated that ectopic HOPX expression constrains tumor growth and that RNA interference knockdown of endogenous HOPX rebuilt it, advocating its strong tumor-suppressor action $(14,15)$. Its inactivation mechanism during cancer pathogenesis usually involves promoter methylation $(8,13,16)$. Two $H O P X$ promoters have been reported and recent studies indicates that there are five splice variants HOPX (16). However, only HOPX- $\beta$ (NM 139211.2) promoter harbors CpG islands including the first exon and intron (13). Its epigenetic control has been correlated with tumorigenesis and worse prognosis in uterine, breast, esophageal, gastric, pancreatic and colorectal cancers $(10,11,12,13,15,17$, 18). However, the correlation between HOPX- $\beta$ and DTC remains unknown with only one study, involving six papillary thyroid cancer (PTC) samples, which showed upregulation in four PTC tumors, contrasting with previously described downregulation observed in other types of cancer (19). In the present study, we investigated the HOPX- $\beta$ gene expression and promoter methylation status in DTC tissues, cancer cell lines and in thyroid cancer samples from The Cancer Genome Atlas (TCGA) database. The clinical relevance of HOPX expression and methylation was also studied.

\section{Methods}

\section{Clinical specimens}

From August 2013 till September 2013, paraffin-embedded thyroid tumor tissues ( $\mathrm{T}$ ) and paired non-tumor parenchyma (NT) were collected from consecutive patients diagnosed with stage I to III DTC and thyroid benign lesions that were submitted to surgery at São Rafael Hospital. NT tissue was defined as the adjacent area to the site of the lesion with no histologic signs of abnormal pathology. All samples with evidence of chronic lymphocytic thyroiditis were excluded, in an attempt to minimize differences due autoimmune disease. TNM and risk of recurrence classification was made according to the American Joint Committee on Cancer (AJCC) 7th edition and ATA guidelines (American Thyroid Association) staging system, respectively $(20,21)$.

A total of 27 patients were included in the current study. Of these, 21 patients were diagnosed with stage I to III DTC and 6 patients with thyroid benign lesions (two follicular adenomas and four hyperplastic nodules). Clinical and pathological data of all DTC patients are described in Table 1. Due to the reduced amount of tissue available, three other T (PTC) and NT samples from a previous study (22) were included to investigate protein expression. This study was approved by the Federal University of Bahia - Ethical Committee for Research Projects.

\section{Quantitative polymerase chain reaction}

Total RNA was obtained using the TRIzol method, reverse-transcribed with SuperScript III reverse transcriptase kit (Life Technologies) and quantified with Nanoespectrophotometer (KASVI, Curitiba, PR). Quantitative real-time PCR (qRT-PCR) was carried out and normalized to S8 gene expression using Platinum SYBR Green Master Mix (SYBR Green I Dye, AmpliTaq Gold DNA Polymerase, dNTPs with dUTP, Passive Reference I, Buffer) and a 7500 Real-Time PCR System (Life Technologies) in conditions previously reported (15).

\section{Western blot analysis}

Immunoblotting (10\% SDS-PAGE) was performed with primary HOPX antibody (1:1000; Cell Signaling) 


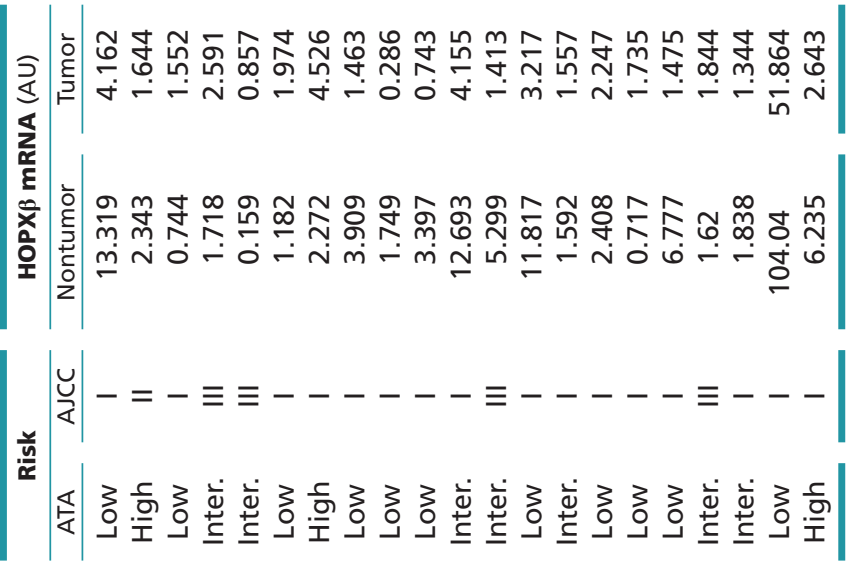

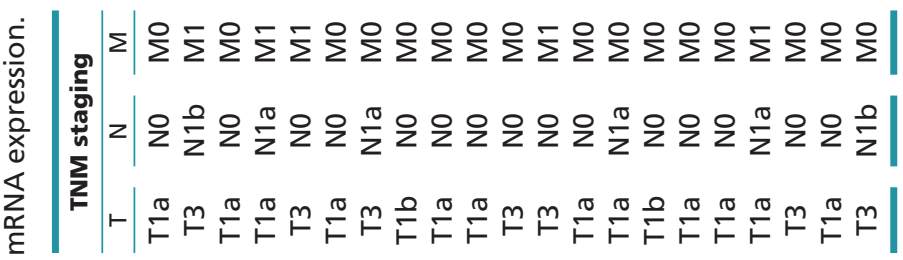

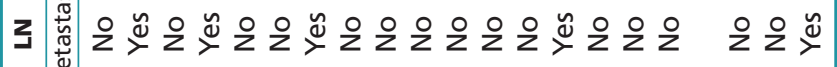

$$
\text { ฮั }
$$

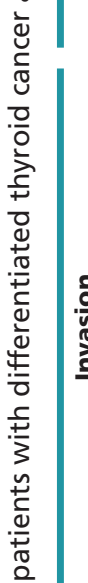$$
\text { 咅| }
$$ 
and tubulin antibody (1:10,000; Sigma-Aldrich). Band densitometry was performed using ImageQuant LAS 4000 (GE Healthcare Life Sciences).

\section{Cell treatment with 5-Aza-dC demethylating agent}

To quantify HOPX- $\beta$ gene expression, tumor cell lines FTC238 (catalog no. 94060902), FTC236 (catalog no. 06030202), WRO (metastatic thyroid FTC cell lines, ECACC; Health Protection Agency Culture Collection; depositor, J Köhrle and Orlo Clark) were treated with 5-aza-2'-deoxycytidine (5-Aza-dC, Sigma-Aldrich). Cells $\left(5.0 \times 10^{5}\right)$ were grown at $37^{\circ} \mathrm{C}$ in $5 \% \mathrm{CO}_{2}$ for 4 consecutive days in adequate culture medium plus $15 \mu \mathrm{m}$ 5-Aza diluted in dimethyl sulfoxide (DMSO) (Sigma-Aldrich) or DMSO alone as an experimental control. All assays were performed in triplicate. At the end of the treatment, total RNA and genomic DNA were obtained for subsequent analysis of HOPX- $\beta$ and S8 mRNA expression by real-time PCR.

\section{Quantitative methylation-specific PCR (Q-MSP)}

Genomic DNA was obtained with the Gentra Puregene Kit (QIAgen). For quantitative methylation analysis, all reactions were performed in triplicate. Primer sequences for $H O P X-\beta$ and $\beta$-actin have been previously described (15). With $18 \mu \mathrm{L}$ total volume reaction containing $20 \mathrm{ng}$ of DNA previously treated with EpiTect Bisulfite (QIAgen), the PCR was performed with 7500 FAST Real-Time PCR System (Life Technologies) in conditions of $95^{\circ} \mathrm{C}$ for $3 \mathrm{~min}$, followed by 45 cycles of $95^{\circ} \mathrm{C}$ for $20 \mathrm{~s}, 60^{\circ} \mathrm{C}$ for $30 \mathrm{~s}$ and $72^{\circ} \mathrm{C}$ for $30 \mathrm{~s}$. The same previously reported DNA region was chosen for Q-MSP, which examined HOPX- $\beta$ methylation in gastric and colorectal cancer and enclosed nine CpG sites $(10,17)$. The samples were considered to be methylated when amplification was detected in at least two triplicates. EpiTect Control DNA (Qiagen) served as a positive control and generated standard curves from 1.5 dilution series. Percent Methylated Reference (PMR) was calculated using a procedure previously described (23). In brief, the PMR was calculated as the ratio of the median value of the HOPX- $\beta$ : $\beta$-actin ratio of each sample divided by the median value of the $H O P X-\beta: \beta$-actin of the fully methylated control DNA and multiplied by 100 with the Cts (cycle thresholds) for all samples converted to a relative quantity scale using a standard curve of diluted methylated DNA. The ratio of the 'quantity' of HOPX- $\beta$ methylated DNA to total $\beta$-actin DNA was calculated for both the samples of interest and the fully methylated control DNA.

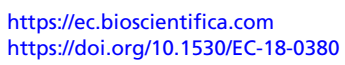

\section{Methylation and expression analysis from The} Cancer Genome Atlas (TCGA) database

A total of 564 samples (508 papillary tumors (T) and 56 non-neoplastic tissues (NT)) of the 580 TCGA thyroid samples (THCA) (515 T, 65 NT) were selected in this study (24) (http://cancergenome.nih.gov). Among them, $55 \mathrm{~T}$ samples paired with NT adjacent samples. Samples without methylations data, classified as poorly differentiated thyroid cancer, from patients that received neoadjuvant therapy prior to resection or without complete clinical data were not selected.

The HOPX methylation beta values from TCGA data (level 2) (24) were collected from Xena Public Data Hubs (https://xena.ucsc.edu/). From the 25 HOPX CpG sites with methylation data, six $C p G$ sites within the $C p G$ island of the HOPX- $\beta$ promoter were considered relevant and the methylation value of the island was calculated as the sum of their beta values (25). To categorize T samples as hyper-methylated threshold methylation value of 1.89 was determined considering the distribution of the beta value for normal and $\mathrm{T}$ samples as previously described (25).

HOPX expression data were also collected from Xena Public Data Hubs as the RSEM value (normalized expectation maximization value) for gene expression (polyA+Illumina Hiseq) (level 3). The clinical data of these patients was download from Cbioportal for cancer genomics (level 3) (http://www.cbioportal.org/ study?id=thca_tcga\#clinical) (26). Clinical and pathologic characteristics are presented in Supplementary Table 1 (see section on supplementary data given at the end of this article).

\section{Statistical analysis}

All data were analyzed with SSP version 22 or GraphPrim 6. Results were expressed as mean \pm s.D. or median (maximum-minimum). The $\chi^{2}$ test or Fisher exact test was used for categorical variables and Student's $t$ test, Wilcoxon matched-pairs signed-rank test for nonparametric data, ANOVA and Pearson correlation test were used for continuous variables. Fisher exact tests, $\chi^{2}$ test and multivariate logistic regression analysis were performed for correlation analysis of $H O P X-\beta$ promoter methylation status with clinic-pathologic parameters. Kaplan-Meier method using log-rank test was used for survival analysis and Cox proportional hazard model for multivariate prognosis analysis. The value of $P<0.05$ was considered significant.

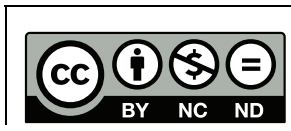
This work is licensed under a Creative Commons
Attribution-NonCommercial-NoDerivatives 4.0 International License. 


\section{Results}

$H O P X-\beta$ expression and methylation status in thyroid cancer cells cultures

Cell cultures of FTC236, FTC238 and WRO were treated with 5-Aza-dC to investigate $H O P X-\beta$ expression and methylation. The HOPX- $\beta$ mRNA mean normalized expression was significantly higher in WRO cells treated with 5-Aza compared to untreated cells $(2.85 \pm 0.44 \mathrm{AU}$; $8.76 \pm 1.05 \mathrm{AU}, P=0.03)$. Similar result was observed in FTC236 $(0.085 \pm 0.04 \mathrm{AU} ; 1.176 \pm 0.055 \mathrm{AU})$ but not significant (Fig. 1A). The PMR (percent of methylated reference) values of $\operatorname{HOPX} \beta$ promoter methylation were reduced in FTC238 $(1.47 \pm 0.38 \mathrm{AU} ; 0.38 \pm 0.11 \mathrm{AU})$ and in WRO 5-AZA-treated cells $(5.08 \pm 1.37 \mathrm{AU} ; 2.74 \pm 0.025$ AU) (not significant) compared with untreated cells (Fig. 1B). The HOPX protein expression was higher in FTC238 5-AZA-treated cells compared with untreated cells (Fig. 1C). In FTC236 cells no change in HOPX- $\beta$ mRNA and protein expression, and methylation values treatment were observed after 5-Aza treatment.

\section{HOPX- $\beta$ expression and methylation status in DTC}

We next compared mRNA levels of $H O P X-\beta$ in 27 patients with malignant thyroid tumors $(n=21)$ or benign thyroid tumors $(n=6)$ with a matched adjacent NT tissue from each of these patients. As seen in Fig. 2A, the malignant tumor samples showed a reduced expression of HOPX- $\beta$ mRNA (1.73 (0.28-51.86) AU) compared with their NT tissue (2.34 (0.16-104.0) AU) $(P=0.02)$. This pattern was sustained when the outlier (sample \#20) was excluded (T: 1.69 (0.28-4.53) AU; NT: $2.37(0.16-13.32)$ AU) $(P=0.04)$. At all 14/21 (67\%) pairs had lower HOPX- $\beta$ mRNA expression in the malignant tumor sample compared to their NT parenchyma tissue (Table 1). As for the six patients with benign lesions (Fig. 2B), there was no meaningful difference between $H O P X-\beta$ mRNA expression in benign tumor tissues (1.07 (0.13-2.68) AU) when compared with their NT tissue (1.45 (1.26-49.22) AU); however, four of the six pairs of samples showed $\mathrm{T}<\mathrm{NT}$ expression pattern. We found no relationship between HOPX- $\beta$ mRNA downregulation and risk of recurrence classification (21). We then performed methylation analysis in 14 available DTC tumors and matched NT samples. Figure 3 shows a tendency of increased overall PMR in tumor samples (0.31 (0.02-1.88) AU) compared with NT paired sample (0.13 (0.003-1.02) AU) $P=0.055$. Among them, in $10(71.4 \%)$ samples the tumor methylation status was increased compared to paired NT. Figure 4 details

$\begin{array}{lr}\text { https://ec.bioscientifica.com } & \text { ○ } 2018 \text { The authors } \\ \text { https://doi.org/10.1530/EC-18-0380 } & \text { Published by Bioscientifica Ltd }\end{array}$
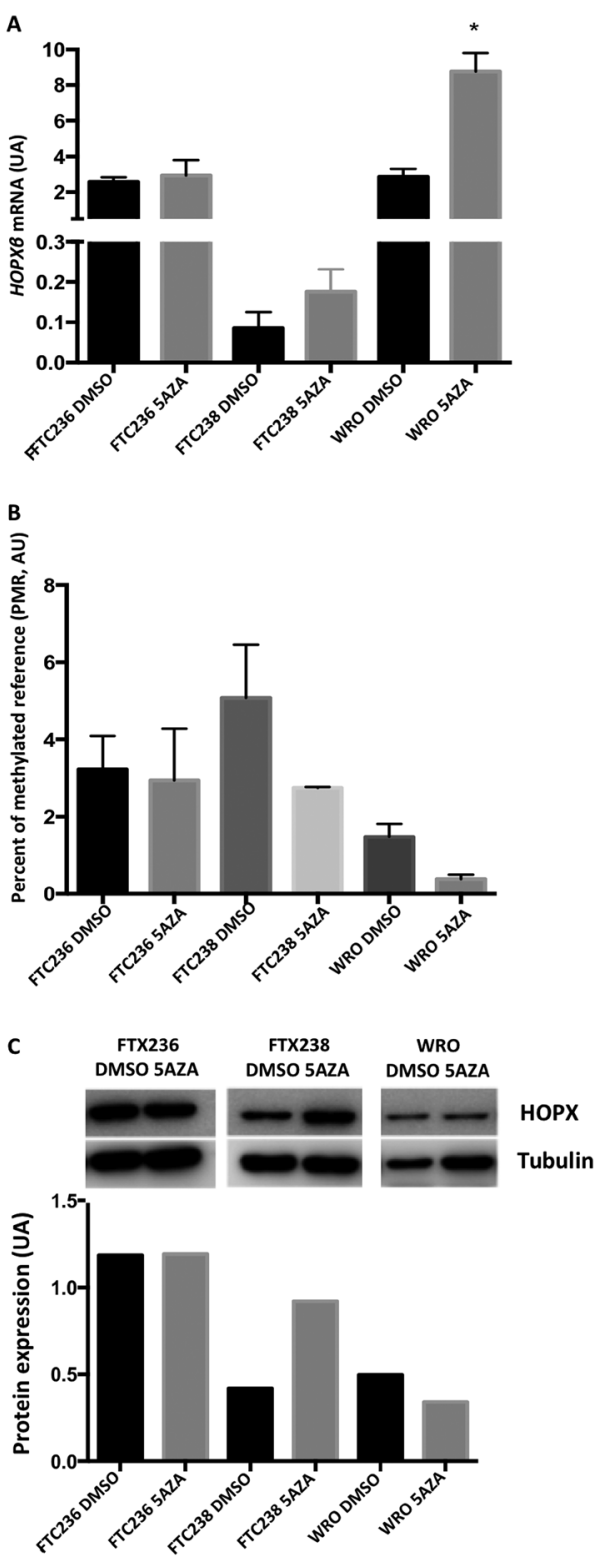

Figure 1

HOPX- $\beta$ mRNA (A) and protein expression (C), and PMR (percent of methylated reference) values of HOPX $\beta$ promoter methylation (B) before (DMSO) and after (5AZA) treatment with the demethylating agent 5-AzadC in cell cultures of FTC236, FTC 238 and WRO. ( $* P=0.03$ between control and treated cells.) AU, arbitrary units.

the results by patient in which 6 of the $14(42.8 \%)$ did present downregulation of HOPX- $\beta$ mRNA coupled with promoter methylation. In evaluating this particular subset of patients in comparison to the six patients who did not show a pattern of promoter methylation and gene silencing, we found no evident correlation with any clinical variable. Due to the reduced quantities of tissue available of these samples for HOPX protein expression analysis was investigated in three other thyroid samples

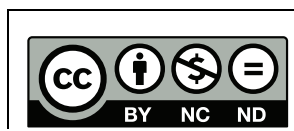

This work is licensed under a Creative Commons Attribution-NonCommercial-NoDerivatives 4.0 International License. 
A

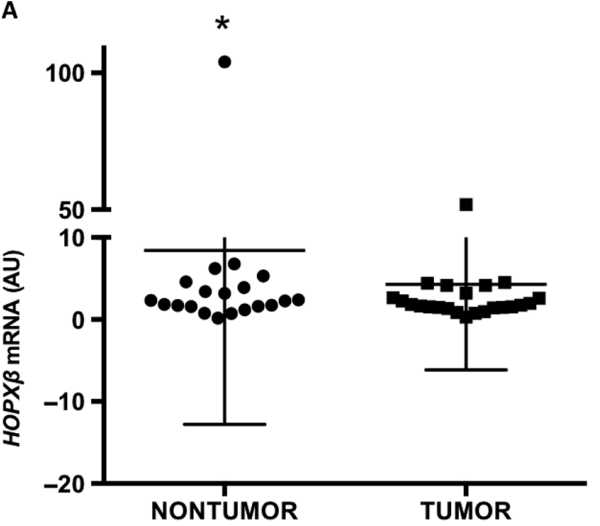

B

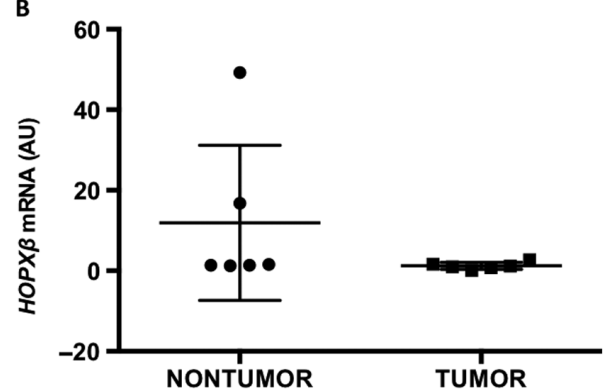

Figure 2

Expression level of $H O P X-\beta$ mRNA in different primary thyroid tumors (A) malignant group, $n=21$; (B) benign group, $n=6$; and their matched non-tumor tissues determined by qRT-PCR. Reduced expression in tumor compared with non-tumor samples was observed in malignant groups $\left({ }^{*} P=0.03\right) . \mathrm{AU}$, arbitrary units.

(T/NT) (patients 22, 23 and 24) (22). Reduced HOPX- $\beta$ mRNA expression concomitant with discrete high PMR in T compared with NT was observed in the three samples pairs (mRNA 22-T: 2.497 AU, 22-NT: 122.23 AU; 23 T: 4.436 AU, 23 NT: 4.595 AU; 24 T: 0.959 AU, 24 NT: 3.183 AU) (PRM 22 T: 1.240\%, 22 NT: 1.195\%; 23 T: 1.185\%, 23 NT: 1.180\%; 24 T: 0.965 UA, 24 NT: 0.925\%). Accordingly, the western blot analysis showed reduced protein expression in the T samples compared with NT samples in the three cases (Fig. 5).

\section{HOPX expression and methylation analysis using TCGA data}

The analysis of HOPX gene expression from TCGA data showed no differences in $\mathrm{T}(12.15 \pm 8.1 \mathrm{AU})$ and $\mathrm{NT}$ samples $(12.14 \pm 4.7 \mathrm{AU})$, as well as for the paired samples (T: $12.02 \pm 1.1$; NT: $12.14 \pm 4.7)$. Differences in $H O P X$ expression were observed between the subtype of PTC, tall cells showed higher expression $(12.49 \pm 0.7)$ than follicular variant $(11.98 \pm 0.8)(P=0.006)$. The presence of BRAF mutation was associated neither with the expression

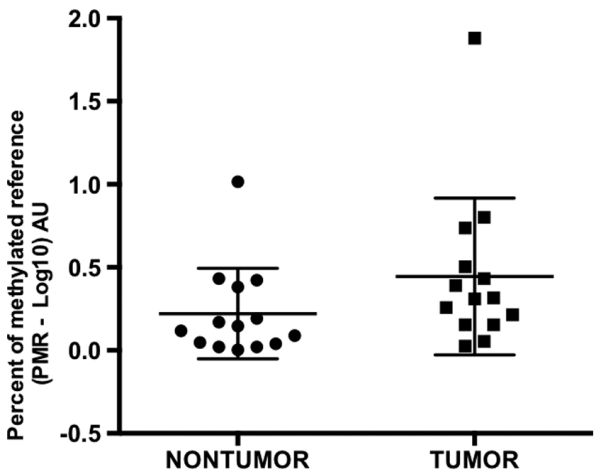

Figure 3

PMR (percent of methylated reference) values of $H O P X-\beta$ promoter methylation in differentiated thyroid cancer (tumor) $(n=14)$ and their matched non-tumor tissues determined by Q-MSP (quantitative methylated PCR). A tendency of high degree of methylation was observed in the malignant tumor samples compared to the matched surrounding non-tumor samples $(P=0.055)$. AU, arbitrary units.

values nor with methylation status. No negative correlation was observed between HOPX expression and the methylation value of the CpG island or of each of the six selected CpG site, in tumors, non-tumors, all samples ( $\mathrm{T}$ and NT) and in the paired samples. Considering the 49 paired samples for which methylation and expression data were available, in 22 cases (44.9\%) lower methylation value was observed in T samples compared with NT while $13 \mathrm{~T}$ samples (26.5\%) showed concomitant reduction of HOPX expression.

Regarding HOPX methylation from TCGA data, significant high methylation level in $\mathrm{T}(1.63 \pm 0.8)$ compared with NT samples $(1.24 \pm 0.3, P=0.0005)$ was observed. This result was also detected when classical or follicular variants were analyzed individually and between the paired samples $(P<0.0001$, respectively) (Fig. 6). Considering the histologic types of PTC, the follicular variants showed higher methylation value $(1.93 \pm 0.07)$ compared to tall cell variants $(1.54 \pm 0.1)$ and classical PTC $(1.55 \pm 0.04) \quad(P<0.005)$. We then investigated the correlation between HOPX methylation and clinical features. Higher HOPX methylation values were associated with older age at diagnosis ( $\geq 45$ years) $(P=0.044)$, with recurrent or progressive disease $(P=0.036)$, with reduced survival $(P=0.013)$ and with the presence of new neoplasm event post initial therapy $(P=0.017)$. Interestingly when the analysis was reduced to the tumors of the paired samples only reduced survival correlated with high HOPX methylation $(P=0.05)$. When the samples were categorized as hyper-methylated (methylation threshold $>1.89$ ), 137 of 508 tumor samples (26.9\%) remained in this category and hyper-methylation correlated with older age ( $\geq 45$ years)

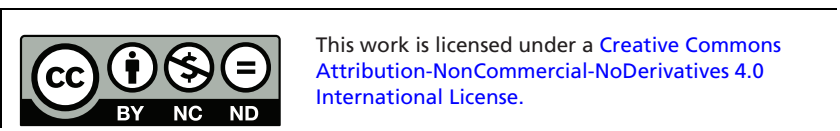




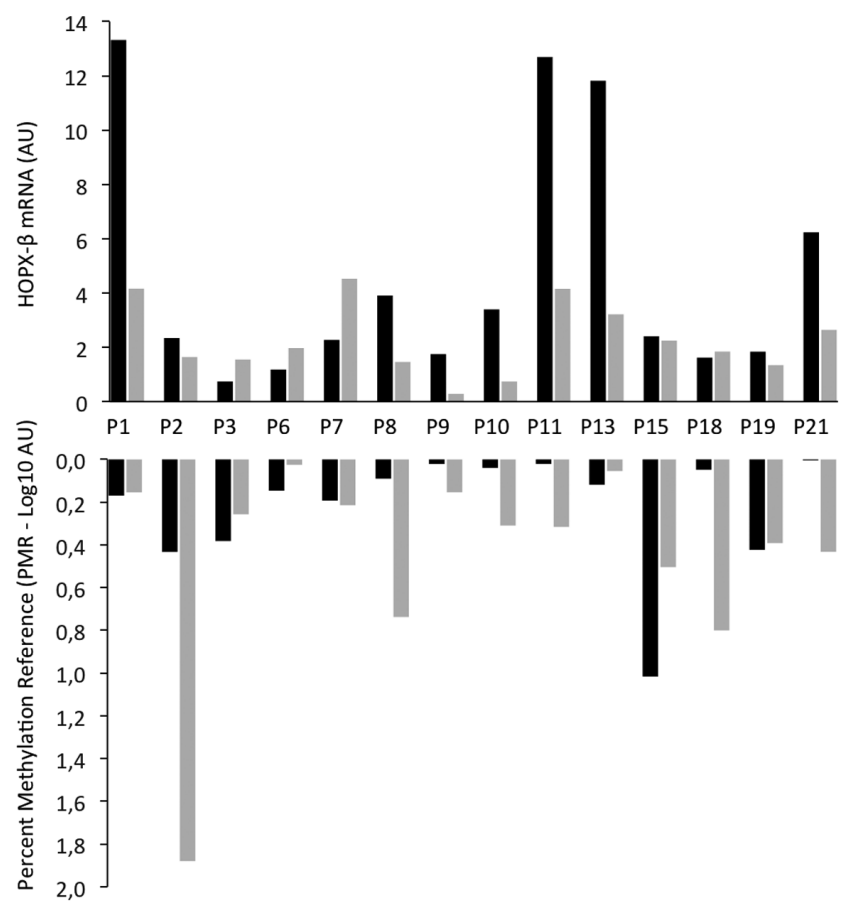

Figure 4

HOPX- $\beta$ mRNA (top panel) and PMR (percent of methylated reference) values of HOPX $\beta$ promoter methylation (bottom panel) in 14/19 pairs of paraffin-embedded DTC samples. AU, arbitrary units; P, patient. Black bar: non-tumor, gray bar: tumor.

$(P<0.001)$ and with follicular variant $(P=0.002)$. KaplanMeier survival analysis showed significant association of hyper-methylation with worse overall survival $(P=0.003)$, worse disease free status $(P=0.008)$ and older age $(P=0.006)$ (Fig. 7). Multivariate Cox analysis with BRAF status and variables that correlates with worse prognosis and univariate analysis showed that hyper-methylation was an independent prognostic factor for worse prognosis $(P=0.012$, Hazard ratio $=4.758,95 \% \mathrm{CI}=1.4-16.1)$. No clinical features correlated with hyper-methylation status when the paired group was categorized.

\section{Discussion}

HOPX has been suggested as a tumor-suppressor gene candidate gene involved in tumorigenesis, downregulating genes linked to angiogenesis and tumor aggressiveness (10). Indeed, the nature of HOPX action can be dependent upon cellular and extracellular signals, as well as cross-talk between important thyroid cancer signaling pathways, such as PI3K and $\operatorname{MAPK}(27,28,29)$. A consistent pattern of downregulation of $H O P X-\beta$ mRNA expression coupled with $H O P X-\beta$ promoter methylation levels in cancer cell lines and in various malign tissue

https://ec.bioscientifica.com
https://doi.org/10.1530/EC-18-0380

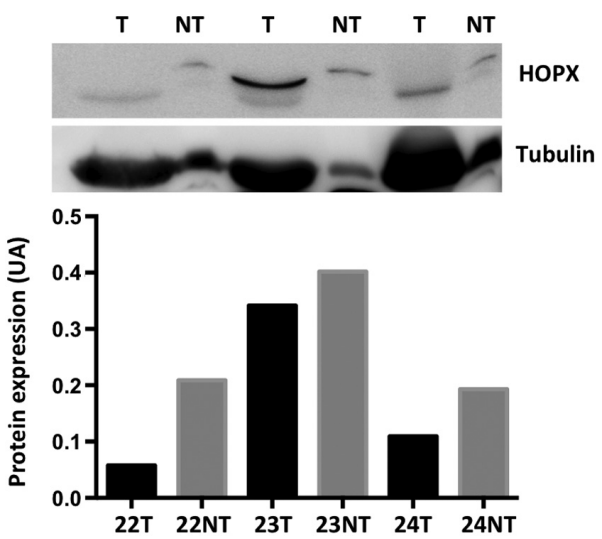

Figure 5

Western blot for HOPX protein expression in three pairs tissue samples (T/NT), 22, 23 and 24 with primary HOPX antibody (1:1000; Cell Signaling) showed reduced expression in the T samples compared with NT samples. Tubulin expression was used as control (1:10,000; Sigma).

types such us esophageal, colorectal, pancreatic in uterine and breast cancers have been previously described $(8,10,11,12,13,15,18)$. On the other hand, in acute myeloid leukemia high HOPX expression was an unfavorable prognostic factor associated with low complete remission rate and short survival (30) and in sarcoma cells it was associated to metastases and its knockdown decreased metastatic activity (31). In this study, we interrogated the expression and
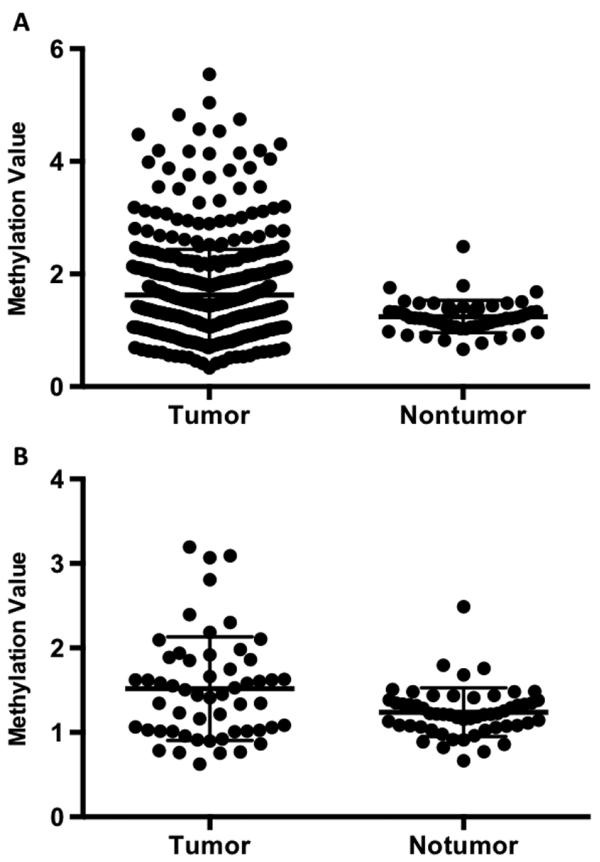

Figure 6

HOPX- $\beta$ methylation values in tumor (T) and non-tumor (NT) groups in all thyroid cancer TCGA samples (A) and in paired samples (B), ${ }^{*} P<0.0005$. 

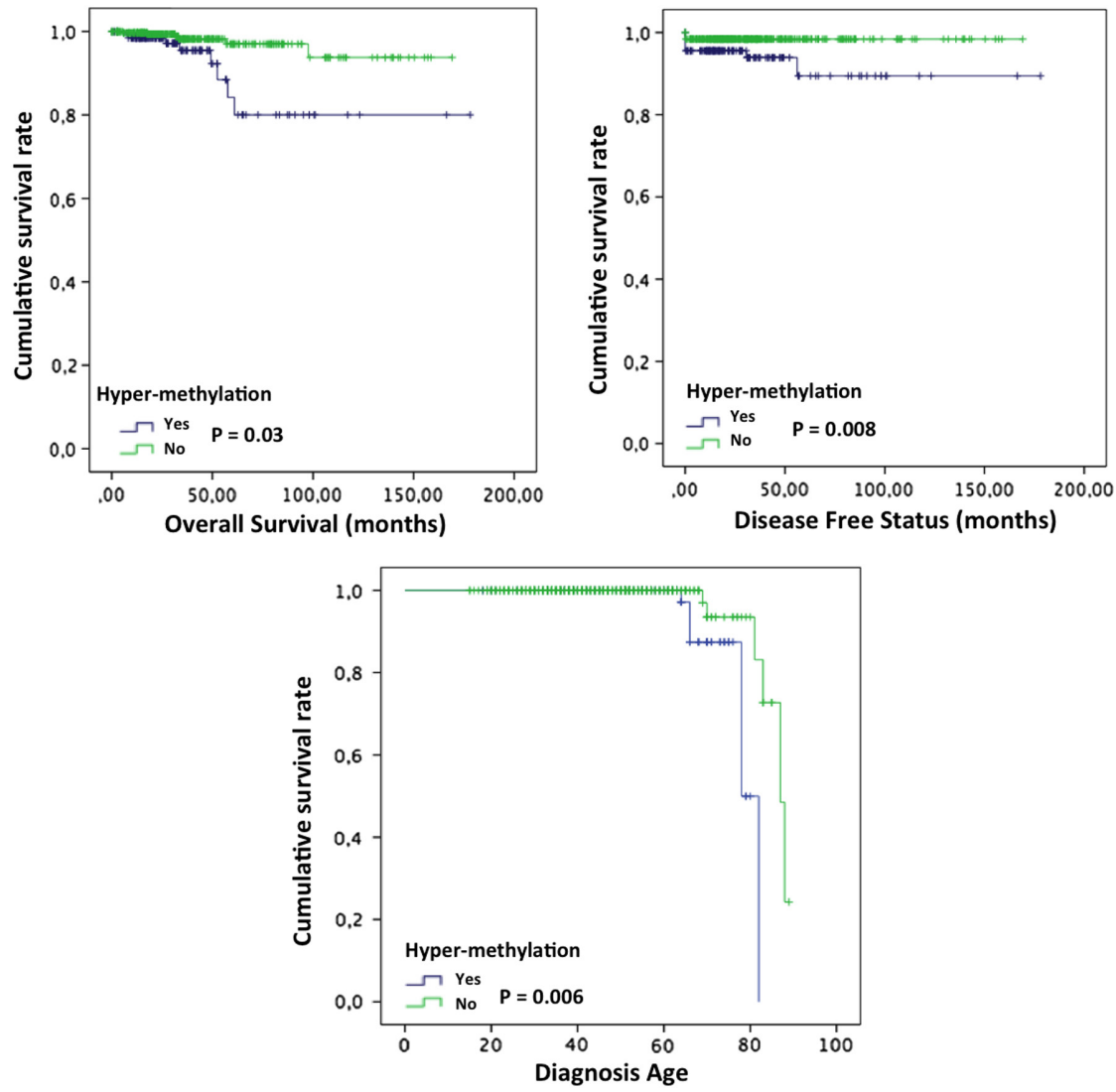

Figure 7

Kaplan-Meier survival analysis using hypermethylation threshold value of 1.89 showed significant association of HOPX promoter methylation with diagnosis age, disease free status and overall survival $(P=0.006, P=0.008$, $P=0.03$, respectively).

methylation status and their clinical relevance in DTC. In investigating HOPX methylation silencing in DTC cancer cells and re-expression by demethylating agent 5 -Aza-dC of HOPX- $\beta$ transcripts evaluated by qRT-PCR, we found that re-expression was recognized in two of the three cancer cell lines analyzed (FTC238 and WRO), concomitantly with reduction in $H O P X-\beta$ promoter methylation. However, protein expression was only increased in FTC238 cells, suggesting that HOPX protein expression depends not only on increased transcription. Our data did also show a considerable downregulation of $H O P X-\beta$ mRNA expression in DTC, along with a trend of high $H O P X-\beta$ promoter methylation. Approximately half of the patient samples studied did find a similar pattern to that reported for other cancers $(8,10,11,12$, 13). The fact that in this study and others $(10,19,25)$ several samples did not show a clear correlation between methylation values and expression suggests that reduction of $H O P X-\beta$ mRNA could be partially explained by epigenetic alterations, though $H O P X-\beta$ promoter methylation is one of mechanism for inactivation. In evaluating HOPX- $\beta$ mRNA expression in benign tumors and their adjacent non-tumor samples, four of six paired samples showed reduced tumor expression, an extended study using a larger sample is necessary to confirm $H O P X-\beta$ mRNA expression levels in benign tumors.

In order to understand the relationship between methylation and HOPX- $\beta$ expression in thyroid cancer we performed a complete analysis of PTC (THYCA) from TCGA dataset (24). No differences in HOPX expression were observed between tumor and non-tumor samples. Nevertheless significant high methylation levels were observed in the tumor samples compared with nontumor, even more the follicular variants had the highest methylation values. No negative correlation was observed between HOPX expression and the methylation status, in contrast, a weak positive correlation between HOPX expression and methylation was observed (data not shown). Similarly, in the BRCA dataset, over-expressed HOPX showed differentially hyper-methylated promoter in tumors (32) and in head and neck cancer (HNSCC dataset) 17 of 20 paired samples showed reduced HOPX tumor expression but only three of them had promoter hyper-methylation (25). As previously mentioned, these data reinforce the concept that HOPX methylation may be in part responsible for the loss of HOPX protein and that other mechanisms may be involved in HOPX expression, such as genetic mutation, histone https://ec.bioscientifica.com

https://doi.org/10.1530/EC-18-0380 (c) 2018 The authors Published by Bioscientifica Ltd
This work is licensed under a Creative Commons Attribution-NonCommercial-NoDerivatives 4.0 International License. 
deacetylation, methylation of other transcription factor genes or inactivation of an upstream tumor-suppressive pathways $(18,32)$. The direct regulation of HOPX through transcription factors has to be also considered.

In the TCGA dataset the presence of BRAF mutation was not associated with the methylation state or gene expression in the tumors. Previously, it was shown that the presence of BRAF V600E mutation promotes aberrant methylation of a large cohort of genes in thyroid cancer cells (33).

Our results showed that high HOPX methylation correlated with worse prognosis in thyroid cancer and was associated with older age at diagnosis, recurrent or progressive disease, reduced survival and with the presence of new neoplasm event post initial therapy. Furthermore HOPX hyper-methylation could be an independent predictor factor for worse prognosis. These data are in line with previous studies in colorectal cancer (10), esophageal squamous carcinoma (13), gastric cancer (17) and breast cancer (18).

Without a doubt, the HOPX biological activity is more complex than expected, studies to explain the relevance of the isoforms, its tissue specificity, its gene expression regulation, the opposite methylation pattern: hyper-methylated in solid tumor while hypo-methylated in acute myeloid leukemia are needed.

In conclusion, the $H O P X$ promoter was methylated in DTC; however, a moderate coupling of downregulation of $H O P X-\beta$ mRNA and protein expression in DTC, followed by high HOPX- $\beta$ promoter methylation was observed, indicating that other mechanisms may be involved in gene expression regulation. Furthermore, high HOPX promoter methylation status was associated with the worse prognosis of DTC patients.

\section{Supplementary data}

This is linked to the online version of the paper at https://doi.org/10.1530/ EC-18-0380.

\section{Declaration of interest}

The authors declare that there is no conflict of interest that could be perceived as prejudicing the impartiality of the research reported.

\section{Funding}

This work was supported in part by grants FAPESB (Fundação de Amparo à Pesquisa no Estado da Bahia, Edital 011/2013; TOU RED010/2013) and FAPESP \# 2013/195983.

\section{Patient consent}

Informed consent has been obtained from the patient for publication.

\section{Acknowledgements}

The authors would like to thank all the participants that contributed samples to this study. In addition they would like to thank Hattie Cobb Medical Writing Services for her editorial support in this publication.

\section{References}

1 Davies L, Morris LG, Haymart M, Chen AY, Goldenberg D, Morris J, Ogilvie JB, Terris DJ, Netterville J, Wong RJ, et al. American Association of Clinical Endocrinologists and American College of Endocrinology disease state clinical review: the increasing incidence of thyroid cancer. Endocrine Practices 201521 686-696. (https://doi. org/10.4158/EP14466.DSCR)

2 Morris LG, Sikora AG, Tosteson TD \& Davies L. The increasing incidence of thyroid cancer: the influence of access to care. Thyroid 201323 885-891. (https://doi.org/10.1089/thy.2013.0045)

3 Baylin SB \& Jones PA. A decade of exploring the cancer epigenome biological and translational implications. Nature Reviews Cancer 2011 11 726-734. (https://doi.org/10.1038/nrc3130)

4 Kondo T, Asa SL \& Ezzat S. Epigenetic dysregulation in thyroid neoplasia. Endocrinology Metabolism Clinics of North America 200837 389-400, ix. (https://doi.org/10.1016/j.ecl.2007.12.002)

5 Esteller M. Epigenetics in cancer. New England Journal of Medicine 2008358 1148-1159. (https://doi.org/10.1056/NEJMra072067)

6 Xing M. Gene methylation in thyroid tumorigenesis. Endocrinology 2007148 948-953. (https://doi.org/10.1210/en.2006-0927)

7 Kook H, Yung WW, Simpson RJ, Kee HJ, Shin S, Lowry JA, Loughlin FE, Yin Z, Epstein JA \& Mackay JP. Analysis of the structure and function of the transcriptional coregulator HOP. Biochemistry 200645 10584-10590. (https://doi.org/10.1021/bi060641s)

8 Yamaguchi S, Asanoma K, Takao T, Kato K \& Wake N. Homeobox gene HOPX is epigenetically silenced in human uterine endometrial cancer and suppresses estrogen-stimulated proliferation of cancer cells by inhibiting serum response factor. International Journal of Cancer 2009124 2577-2588. (https://doi.org/10.1002/ijc.24217)

9 Cheung WK, Zhao M, Liu Z, Stevens LE, Cao PD, Fang JE, Westbrook TF \& Nguyen DX. Control of alveolar differentiation by the lineage transcription factors GATA6 and HOPX inhibits lung adenocarcinoma metastasis. Cancer Cell 201323 725-738. (https:// doi.org/10.1016/j.ccr.2013.04.009)

10 Katoh H, Yamashita K, Waraya M, Margalit O, Ooki A, Tamaki H, Sakagami H, Kokubo K, Sidransky D \& Watanabe M. Epigenetic silencing of HOPX promotes cancer progression in colorectal cancer. Neoplasia 201214 559-571. (https://doi.org/10.1593/neo.12330)

11 Kikuchi M, Katoh H, Waraya M, Tanaka Y, Ishii S, Tanaka T, Nishizawa N, Yokoi K, Minatani N, Ema A, et al. Epigenetic silencing of HOPX contributes to cancer aggressiveness in breast cancer. Cancer Letters 2016384 70-78. (https://doi.org/10.1016/j. canlet.2016.10.017)

12 Yamashita K, Katoh H \& Watanabe M. The homeobox only protein homeobox (HOPX) and colorectal cancer. International Journal of Molecular Sciences 201314 23231-23243. (https://doi.org/10.3390/ ijms141223231)

13 Yamashita K, Kim MS, Park HL, Tokumaru Y, Osada M, Inoue H, Mori M \& Sidransky D. HOP/OB1/NECC1 promoter DNA is frequently hypermethylated and involved in tumorigenic ability in esophageal squamous cell carcinoma. Molecular Cancer Research 2008 6 31-41. (https://doi.org/10.1158/1541-7786.MCR-07-0213)

14 Ushiku H, Yamashita K, Kawamata H, Waraya M, Katoh H, Yokoi K, Tanaka T, Ishii S, Nishizawa N, Kikuchi M, et al. Homeobox-only protein expression is a critical prognostic indicator of pancreatic neuroendocrine tumor and is regulated by promoter DNA hypermethylation. Pancreas 201645 1255-1262. (https://doi. org/10.1097/MPA.0000000000000646) 
15 Waraya M, Yamashita K, Katoh H, Ooki A, Kawamata H, Nishimiya H, Nakamura K, Ema A \& Watanabe M. Cancer specific promoter CpG Islands hypermethylation of HOP homeobox (HOPX) gene and its potential tumor suppressive role in pancreatic carcinogenesis. BMC Cancer 201212 397. (https://doi. org/10.1186/1471-2407-12-397)

16 Mariotto A, Pavlova O, Park HS, Huber M \& Hohl D. HOPX: the unusual homeodomain-containing protein. Journal of Investigative Dermatology 2016136 905-911. (https://doi.org/10.1016/j. jid.2016.01.032)

17 Ooki A, Yamashita K, Kikuchi S, Sakuramoto S, Katada N, Kokubo K, Kobayashi H, Kim MS, Sidransky D \& Watanabe M. Potential utility of HOP homeobox gene promoter methylation as a marker of tumor aggressiveness in gastric cancer. Oncogene 201029 3263-3275. (https://doi.org/10.1038/onc.2010.76)

18 Kikuchi M, Katoh H, Waraya M, Tanaka Y, Ishii S, Tanaka T, Nishizawa N, Yokoi K, Minatani N, Ema A, et al. Epigenetic silencing of HOPX contributes to cancer aggressiveness in breast cancer. Cancer Letters 2017384 70-78. (https://doi.org/10.1016/j. canlet.2016.10.017)

19 Pauws E, Sijmons GG, Yaka C \& Ris-Stalpers C. A novel homeobox gene overexpressed in thyroid carcinoma. Thyroid 200414 500-505. (https://doi.org/10.1089/1050725041517020)

20 Brierley JD, Panzarella T, Tsang RW, Gospodarowicz MK \& O'Sullivan B. A comparison of different staging systems predictability of patient outcome. Thyroid carcinoma as an example. Cancer 199779 2414-2423. (https://doi.org/10.1002/(SICI)10970142(19970615)79:12<2414::AID-CNCR18>3.0.CO;2-U)

21 Haugen BR, Alexander EK, Bible KC, Doherty GM, Mandel SJ, Nikiforov YE, Pacini F, Randolph GW, Sawka AM, Schlumberger M, et al. 2015 American Thyroid Association Management Guidelines for adult patients with thyroid nodules and differentiated thyroid cancer: the American Thyroid Association Guidelines Task Force on thyroid nodules and differentiated thyroid cancer. Thyroid 201626 1-133. (https://doi.org/10.1089/thy.2015.0020)

22 Galrao AL, Camargo RY, Friguglietti CU, Moraes L, Cerutti JM, Serrano-Nascimento C, Suzuki MF, Medeiros-Neto G \& Rubio IG Hypermethylation of a New Distal Sodium/Iodide Symporter (NIS) enhancer (NDE) is associated with reduced NIS expression in thyroid tumors. Journal of Clinical Endocrinology and Metabolism 201499 E944-E952. (https://doi.org/10.1210/jc.2013-1450)

23 Silverman AL, Park JG, Hamilton SR, Gazdar AF, Luk GD \& Baylin SB. Abnormal methylation of the calcitonin gene in human colonic neoplasms. Cancer Research 198949 3468-3473.
24 Cancer Genome Atlas Research Network. Integrated genomic characterization of papillary thyroid carcinoma. Cell 2014159 676-690. (https://doi.org/10.1016/j.cell.2014.09.050)

25 Yap LF, Lai SL, Patmanathan SN, Gokulan R, Robinson CM, White JB, Chai SJ, Rajadurai P, Prepageran N, Liew YT, et al. HOPX functions as a tumour suppressor in head and neck cancer. Scientific Reports 2016 6 38758. (https://doi.org/10.1038/srep38758)

26 Cerami E, Gao J, Dogrusoz U, Gross BE, Sumer SO, Aksoy BA, Jacobsen A, Byrne CJ, Heuer ML, Larsson E, et al. The cBio cancer genomics portal: an open platform for exploring multidimensional cancer genomics data. Cancer Discovery 20122 401-404. (https://doi. org/10.1158/2159-8290.CD-12-0095)

27 Menges CW \& McCance DJ. Constitutive activation of the RafMAPK pathway causes negative feedback inhibition of Ras-PI3K-AKT and cellular arrest through the EphA2 receptor. Oncogene 200827 2934-2940. (https://doi.org/10.1038/sj.onc.1210957)

28 Moelling K, Schad K, Bosse M, Zimmermann S \& Schweneker M. Regulation of Raf-Akt cross-talk. Journal of Biological Chemistry 2002 277 31099-31106. (https://doi.org/10.1074/jbc.M111974200)

$29 \mathrm{Wu}$ W, Pew T, Zou M, Pang D \& Conzen SD. Glucocorticoid receptorinduced MAPK phosphatase-1 (MPK-1) expression inhibits paclitaxelassociated MAPK activation and contributes to breast cancer cell survival. Journal of Biological Chemistry 2005280 4117-4124. (https:// doi.org/10.1074/jbc.M411200200)

30 Lin CC, Hsu YC, Li YH, Kuo YY, Hou HA Lan, KH, Chen TC, Tzeng YS, Kuo YY, Kao CJ, et al. Higher HOPX expression is associated with distinct clinical and biological features and predicts poor prognosis in de novo acute myeloid leukemia. Haematologica 2017102 1044-1053. (https://doi.org/10.3324/ haematol.2016.161257)

31 Kovarova D, Plachy J, Kosla J, Trejbalova K, Cermak V \& Hejnar J. Downregulation of HOPX controls metastatic behavior in sarcoma cells and identifies genes associated with metastasis. Molecular Cancer Research 201311 1235-1247. (https://doi.org/10.1158/1541-7786. MCR-12-0687)

32 Lin IH, Chen DT, Chang YF, Lee YL, Su CH, Cheng C, Tsai YC, Ng SC, Chen HT, Lee MC, et al. Hierarchical clustering of breast cancer methylomes revealed differentially methylated and expressed breast cancer genes. PLOS ONE 201510 e0118453. (https://doi.org/10.1371/ journal.pone.0118453)

33 Hou P, Liu D \& Xing M. Genome-wide alterations in gene methylation by the BRAF V600E mutation in papillary thyroid cancer cells. Endocrine-Related Cancer 201118 687-697. (https://doi. org/10.1530/ERC-11-0212)

Received in final form 11 October 2018

Accepted 24 October 2018

Accepted Preprint published online 26 October 2018
This work is licensed under a Creative Commons Attribution-NonCommercial-NoDerivatives 4.0 International License. 